\title{
Use of Antipsychotics in Patients with Behavioral and Psychological Symptoms of Dementia: Results of a Spanish Delphi Consensus
}

\author{
Sagrario Manzano-Palomo ${ }^{a} \quad$ Luis F. Agüera-Ortiz ${ }^{b} \quad$ Alexandre García-Caballeroc \\ José Martínez-Raga ${ }^{d}$ Tomás Ojea-Ortega ${ }^{e}$ Raquel Sánchez-Valle ${ }^{f}$ \\ Manuel Antón-Jiménez ${ }^{g}$ José A. Monge-Argilés ${ }^{h} \quad$ Isabel Ramos-García ${ }^{i}$ \\ aDepartment of Neurology, Hospital Universitario Infanta Leonor, Madrid, Spain; ${ }^{b}$ Department of Psychiatry, \\ Hospital Universitario 12 de Octubre, Instituto de Investigación Sanitaria Hospital Universitario 12 de \\ Octubre (imas12), CIBERSAM, Madrid, Spain; 'Department of Psychiatry, Hospital Universitario de Ourense,

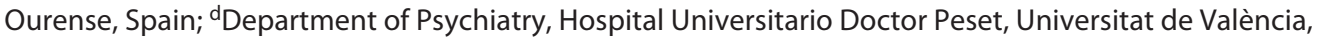 \\ Valencia, Spain; 'Department of Neurology, Hospital Regional Universitario Málaga, Málaga, Spain; ${ }^{\mathrm{f}}$ Alzheimer's \\ Disease and Other Cognitive Disorders Unit, Department of Neurology, Hospital Clinic de Barcelona, Universitat de \\ Barcelona, Barcelona, Spain; ${ }^{9}$ Department of Geriatric Medicine, Complejo Hospitalario Universitario de Cáceres, \\ Cáceres, Spain; hepartment of Neurology, Hospital General Universitario de Alicante, Instituto de Investigación \\ Sanitaria y Biomédica de Alicante, Alicante, Spain; 'Department of Psychiatry, Hospital Clínico Universitario \\ San Carlos, Madrid, Spain
}

\section{Keywords}

Antipsychotics · Alzheimer's disease - Behavioral and psychological symptoms · Consensus · Delphi technique · Dementia $\cdot$ Neuropsychiatric symptoms

\begin{abstract}
Background: Behavioral and psychological symptoms of dementia (BPSD) are difficult to manage and associated with poor outcome. Objectives: The aim of this study was to reach consensus on the use of antipsychotics in patients with BPSD in Spain. Methods: A qualitative, multicenter, two-round Delphi study was carried out, with the participation of specialists involved in the care of dementia patients throughout Spain. They completed a 76-item questionnaire related to the identification of BPSD, treatment with antipsychotics, follow-up of patients, barriers for the use of atypical antipsy-
\end{abstract}

karger@karger.com www.karger.com/dem

Karger $\frac{1}{\%}$

GOPEN ACCESS
(C) 2020 The Author(s)

Published by S. Karger AG, Basel

This article is licensed under the Creative Commons AttributionNonCommercial-NoDerivatives 4.0 International License (CC BYNC-ND) (http://www.karger.com/Services/OpenAccessLicense) Usage and distribution for commercial purposes as well as any distribution of modified material requires written permission. chotics, and effects of antipsychotics on quality of life. $\boldsymbol{R e}$ sults: A total of 162 specialists in neurology, psychiatry, and geriatrics (61\% men) with a mean (SD) age of 45.9 (10) years participated in the study. Almost all participants (96.9\%) strongly agreed that atypical antipsychotics are safer and better tolerated than typical antipsychotics. There was agreement on the importance to review the indication and dose of the antipsychotic drug at least every 3 months. There was consistent high rate of agreement on the beneficial impact of atypical antipsychotics on the quality of life of patients with dementia and their caregivers. A consensus was also reached on the need of detecting BPSD in patients with dementia as it decreases the quality of life of both patients and caregivers, and the need to routinely screen for dementia in elderly patients with no previous psychiatric history in the presence of suggestive symptoms of BPSD. Finally, the participants in the study agreed that administrative barriers 
for the prescription of atypical antipsychotics in Spain hinder the access to this drug group and favor the prescription of typical antipsychotics. Conclusions: The participants in the study agreed that atypical antipsychotics should be preferred to typical antipsychotics in the management of BPSD. Wide consensus was reached about the importance of early identification of BPSD in persons with cognitive impairment, the use and management of atypical antipsychotic drugs and their favorable impact on patients and caregiver's quality of life.

(C) 2020 The Author(s)

Published by S. Karger AG, Basel

\section{Introduction}

Behavioral and psychological symptoms of dementia (BPSD) are a group of noncognitive symptoms and potentially disruptive behaviors in individuals with dementia, associated with significant functional and clinical impairment and a negative impact on the course of the illness, treatment, and carers [1].BPSD represent a common and heterogeneous group of psychopathological features that may occur as isolated symptoms but more commonly appear simultaneously in the same patient. BPSD include aberrant motor behavior, agitation, delusions, hallucinations, depression, anxiety, psychosis, irritability, apathy, disinhibition, and sleep or appetite changes [24]. In a systematic review and meta-analysis of 48 crosssectional or longitudinal studies with the aim to investigate the prevalence of neuropsychiatric symptoms in patients with Alzheimer's dementia (AD), apathy was the most frequent symptom (49\%) followed by depression, aggression, anxiety and sleep disorders, irritability, appetite disorder, aberrant motor behavior, delusion, disinhibition, and hallucination, while the least common neuropsychiatric symptom was euphoria [4]. Duration of illness, age, and years of education explained some of the variance in the prevalence estimates across studies [4]. It is estimated that BPSD affect up to $90 \%$ of all individuals with dementia over the course of their illness [5] and are an integral part of the dementia syndrome. They are independently associated with increased morbidity, impact on the cost of care, and poor outcomes, including cognitive and functional decline, deterioration of family and professional relationships, early institutionalization, caregiver burden, impairment of quality of life, and risk of death among people with $\mathrm{AD}$ [6].

The neurobiology underlying the clinical manifestations of BPSD is still unclear. It has been shown that BPSD are not merely an epiphenomenon of cognitive impairment but could be attributed to specific brain dysfunctions with involvement of different brain regions, fronto-subcortical circuits, cortico-cortical networks, and alterations of neurotransmitter systems in the context of a complex interplay of genetic, neuropathological, and neurochemical mechanisms [7-9]. However, the causes and risk factors for BPSD in an individual patient are multiple and include the combination of biological, psychological, and environmental variables, rather than any specific factor. Thus, treatment of BPSD is often challenging due to the multi-morbidity present in patients with dementia and the complex etiopathogenesis of highly variable symptoms with numerous precipitating, modulating, and vulnerability factors [10]. Individualized treatment plans must include adequate management of concomitant somatic diseases, effective pain relief, non-pharmacological interventions, and pharmacotherapy. Inadequately controlled BPSD may precipitate inpatient admission and may hinder individuals from living at home with their relatives or in residential settings [11]. Furthermore, with the aging of the population leading to an epidemic of $\mathrm{AD}$, effective and safe treatments for BPSD are needed.

In relation to pharmacological management of BPSD, psychotropic medications especially antipsychotics are widely used to treat agitation and associated behavioral symptoms in patients with BPSD, but efficacy data are inconsistent [12]. Adverse effects are an important consideration, given the age and comorbidity of patients with dementia [13], and there are concerns regarding an increased risk of mortality that has been associated with these medications $[14,15]$. A recent network meta-analysis of 17 randomized clinical trials and 5,373 patients with $\mathrm{AD}$, vascular, Lewy body, or mixed dementia assessed the relative benefits and safety of atypical antipsychotics in the treatment of BPSD [16]. Aripiprazole, quetiapine, and risperidone were associated with significantly better outcomes on various effectiveness measures associated with BPSD, while risperidone and olanzapine were associated with an increased risk of cardiovascular adverse events compared with placebo. However, there were no significant differences between atypical antipsychotics in effectiveness, risk of death, or cardiovascular adverse events [16]. In addition, a series of administrative factors often hinder the access of patients with BPSD to atypical antipsychotics, including the lack of an approved indication for the management of BPSD, regional regulatory and bureaucratic differences, or the type of facility the patient is attending or is living in.
Manzano-Palomo et al. 
Therefore, it seemed necessary to provide guidelines at the national level in order to standardize and to improve the management of BPSD patients in clinical practice. The primary aim of the project was to develop a consensus document on the use of antipsychotics in patients with BPSD. The secondary aim was to reach consensus on other aspects of clinical practice of BPSD based on the criteria of specialists involved in the care of patients with different types of dementia.

\section{Materials and Methods}

\section{Study Design}

This was a qualitative, multicenter, two-round Delphi study (the APADE study). APADE is the Spanish acronym for "Uso de Antipsicóticos en PAcientes con DEmencia" (Use of Antipsychotics in Patients with Dementia). The study was conducted over a 4-month period, from March to June 2019. According to regulations of the Spanish Agency of Medicines and Medical Devices (AEMPS), procedures described in the order SAS/3470/2009 of December and in the royal decree 1090/2015 of December 4 regarding postauthorization studies and clinical trials with drugs, respectively, are not applicable. The study is therefore exempt from requiring approval by a Clinical Research Ethics Committee (CEIC) and by the AEMPS.

\section{Participants and Procedures}

A multidisciplinary panel of 9 clinically active specialists (4 neurologists, 4 psychiatrists, and 1 geriatrician) with a special interest and large experience in the management of BPSD were recruited to form the scientific committee of the study. They were responsible for the development of the questionnaire, supervision of the progression of the study, including the recruitment of participants, and the analysis and interpretation of the data.

The final questionnaire was divided into 7 sections: sections 1 and 2 included 13 items with questions related to general data of participants and their clinical practice; section 3 included 13 items that addressed the identification of BPSD in subjects with dementia; section 4 had 28 items focusing on the indication, safety, and tolerability of antipsychotics, and their use in special cases (nursing home, inpatient, fragility, comorbidity); section 5 included 9 items with questions related to the follow-up and management of patients with BPSD; section 6 had 6 items related to barriers to the use of atypical antipsychotics; and section 7 included 7 items that addressed the impact of atypical antipsychotics in the quality of life. The study questionnaire is included in the online suppl. material (see www.karger.com/doi/10.1159/000510566 for all online suppl. material). Questions were formulated so that they could be answered using a 5-point Likert scale, from 1 = "strongly agree," 2 = "moderately agree," 3 = "neither agree nor disagree," $4=$ "moderately disagree," and 5 = "strongly disagree" according to the participant's opinion with respect to what should be performed in clinical practice. The final document emerged from a two-round Delphi consensus process [17].

Study participants were experienced, practicing specialists in neurology, psychiatry, or geriatrics attending a minimum of 10 patients with BPSD every month in either public or private institu- tions throughout Spain. Participation in the study was anonymous. The questionnaire was lodged in an Internet microsite that could be accessed via a weblink included in the e-mail. Only physicians who provide written consent to participate in the study were provided with the microsite URL and the user's password.

\section{Statistical Analysis}

For the purpose of the study, consensus was defined as general agreement of a substantial majority (greater than 75\%) of Delphi panelists in favor or against the recommendation [18]; that is, when the sum of responses "strongly agree" (Likert score 1) and "moderately agree" (Likert score 2) or "strongly disagree" (Likert score 5) and "moderately disagree" (Likert score 5) was greater than $75 \%$ of the total responses obtained for that item, consensus in favor or against was established. When none of these previous assumptions were met, consensus neither for nor against the statement was not reached. Descriptive statistics for categorical variables included frequencies and percentages, and mean and standard deviation for continuous data. The SAS version 9.1.3 was used for data analysis.

\section{Results}

\section{Participants}

Of a total of 170 specialists who were invited to take part in the study, 8 declined to participate due to lack of time. Therefore, the study population included 162 specialists (71 psychiatrists, 60 neurologists, 27 geriatricians, 2 psychogeriatricians, and 2 internal medicine) who agreed to participate in the study. Other specialists were psychogeriatricians. The group included 99 male specialists and 63 female specialists, that had been practicing a mean of 16.3 (10.1) years. Most participants worked in public hospitals $(72.2 \%), 52.1 \%$ of which were tertiary care hospitals. Only $13 \%$ of participants had participated in a training program on BPSD in the previous 12 months, and $7.4 \%$ had participated in a research project on BPSD. In addition, $42.2 \%$ of participants reported that $25-75 \%$ of patients they had seen in the previous week had dementia. With regards to the incidence of BPSD in different types of dementia, $23.6 \%$ of participants stated that they were present in $30-50 \%$ of patients with $\mathrm{AD} ; 24.8 \%$ indicated that these symptoms were seen in $20-30 \%$ of patients with vascular dementia; $26.3 \%$ of participants stated that they were present in more than $50 \%$ of patients with Lewy body dementia, whilst 32.3 and $24.2 \%$ of participants responded that BPSD were seen in less than 5\% of patients with frontotemporal dementia and dementia due to Parkinson's disease, respectively. All these answers referred to the last week. Results of those items in which agreement (or disagreement) was obtained are detailed in Tables 1-3. 
Table 1. Responses to questionnaire items related to the detection of BPSD in patients with dementia

\begin{tabular}{|c|c|c|c|c|c|}
\hline \multirow[t]{2}{*}{ Items of the questionnaire } & \multicolumn{5}{|c|}{ 5-point Likert scale } \\
\hline & $\begin{array}{l}\text { strongly } \\
\text { agree (1) }\end{array}$ & $\begin{array}{l}\text { moderately } \\
\text { agree (2) }\end{array}$ & $\begin{array}{l}\text { neither } \\
\text { agree nor } \\
\text { disagree (3) }\end{array}$ & $\begin{array}{l}\text { moderately } \\
\text { disagree (4) }\end{array}$ & $\begin{array}{l}\text { strongly } \\
\text { disagree (5) }\end{array}$ \\
\hline $\begin{array}{l}\# 14 \text {. The detection of BPSD is very important in patients with dementia because they } \\
\text { decrease significantly the quality of life of patients }\end{array}$ & $144(89.4)$ & $17(10.6)$ & 0 & 0 & 0 \\
\hline $\begin{array}{l}\text { \#15. The detection of BPSD is very important in patients with dementia because they } \\
\text { decrease significantly the quality of life of caregivers }\end{array}$ & $149(92.0)$ & $13(8.0)$ & 0 & 0 & 0 \\
\hline $\begin{array}{l}\# 17 \text {. The presence of visual hallucinations in an elderly patient, with no previous } \\
\text { psychiatric history, suggests applying screening tests for dementia }\end{array}$ & $108(66.7)$ & $47(29.0)$ & $2(1.2)$ & $4(2.5)$ & $1(0.6)$ \\
\hline $\begin{array}{l}\# 19 \text {. The presence of delusional ideas in an elderly patient, with no previous psychiatric } \\
\text { history, suggests applying screening tests for dementia }\end{array}$ & $120(74.1)$ & $41(25.3)$ & 0 & 0 & $1(0.6)$ \\
\hline $\begin{array}{l}\# 20 \text {. The presence of depression in an elderly patient, with no previous psychiatric } \\
\text { history, suggests applying screening tests for dementia }\end{array}$ & $63(38.9)$ & $77(47.5)$ & $18(11.1)$ & $4(2.5)$ & 0 \\
\hline $\begin{array}{l}\# 21 \text {. The presence of apathy/indifference in an elderly patient, with no previous } \\
\text { psychiatric history, suggests applying screening tests for dementia }\end{array}$ & $63(38.9)$ & $82(50.6)$ & $14(8.6)$ & $3(1.9)$ & 0 \\
\hline $\begin{array}{l}\text { \#22. The presence of irritability/emotional lability in an elderly patient, with no } \\
\text { previous psychiatric history, suggests applying screening tests for dementia }\end{array}$ & $60(37.0)$ & $79(48.8)$ & $22(13.6)$ & $1(0.6)$ & 0 \\
\hline $\begin{array}{l}\# 23 \text {. The presence of aberrant motor behavior in an elderly patient, with no previous } \\
\text { psychiatric history, suggests applying screening tests for dementia }\end{array}$ & $62(38.3)$ & $71(43.8)$ & $20(12.3)$ & $9(5.6)$ & 0 \\
\hline$\# 24$. BPSD are more frequent in the different types of dementia as the disease progresses & $78(48.1)$ & $63(38.9)$ & $12(7.4)$ & $9(5.6)$ & 0 \\
\hline $\begin{array}{l}\# 25 \text {. In elderly patients with chronic schizophrenia it can be very difficult to } \\
\text { differentiate whether a change in psychotic symptoms is related to their primary deficit } \\
\text { or is a developing dementia }\end{array}$ & $82(50.6)$ & $61(37.7)$ & $12(7.4)$ & $7(4.3)$ & 0 \\
\hline $\begin{array}{l}\# 26 \text {. In the differentiation between genuine psychosis and psychotic symptoms in } \mathrm{AD} \text {, } \\
\text { it is useful to consider the existence of previous cognitive impairment in } \mathrm{AD} \text { and the } \\
\text { previous history of psychosis in genuine psychosis }\end{array}$ & $99(61.1)$ & $63(38.9)$ & 0 & 0 & 0 \\
\hline
\end{tabular}

Numbers of the items are those of the study questionnaire (online suppl. material). Percentages in parenthesis. BPSD, behavioral and psychological symptoms of dementia; $\mathrm{AD}$, Alzheimer's disease.

\section{Detection of BPSD in a Patient with Dementia}

As shown in Table 1, there was a high number of participants who answered "strongly agree" or "moderately agree" to all the items included under the heading "Detection of BPSD in patients with dementia." A $100 \%$ combined agreement was reached in the items that highlighted the importance of detecting BPSD in patients with dementia as they negatively impact the quality of life of patients and caregivers. Participants also agreed on the need to routinely screen for dementia in elderly patients with no previous psychiatric history if they experience hallucinations, delusions, depression, apathy, irritability, or aberrant motor behavior. Only $18.5 \%$ of participants reported the use of a validated instrument in their practice for the detection of BPSD in patients with dementia, with the Neuropsychiatric Inventory (NPI) as the most commonly used questionnaire (96.7\%). In the presence of visual hallucinations, $68 \%$ of participants identified Lewy body dementia as the type of dementia most commonly associated with this symptom.

\section{Indication of Antipsychotics}

Consensus in favor of the statement was reached in 13 of the 21 items regarding the indication of antipsychotics in the management of BPSD (Table 2). Likewise, consensus against the statement was obtained in 3 of the items. Participants strongly (14.8\%) or moderately (63.9\%) disagreed with the statement that hallucinations responded better to acetylcholinesterase inhibitors than to antipsychotics; they strongly $(49.4 \%)$ or moderately $(38.3 \%)$ disagreed with the statement that the use of atypical antipsychotics for BPSD should be restricted to risperidone, as it is the only one with an approved indication in dementia; and strongly (18.1\%) or moderately (61.9\%) disagreed 
Table 2. Answers to questionnaire items for which consensus was reached on "Indication of antipsychotics in dementia"

\begin{tabular}{|c|c|c|c|c|c|}
\hline Item of the questionnaire & \multicolumn{5}{|c|}{ 5-point Likert scale } \\
\hline $\begin{array}{l}\text { \#27. In patients with BPSD is good practice to initiate treatment with anticholinesterase } \\
\text { inhibitors/memantine before starting treatment with antipsychotics* }\end{array}$ & $47(30.3)$ & $93(60.0)$ & $10(6.5)$ & $5(3.2)$ & 0 \\
\hline $\begin{array}{l}\text { \#29. Use of atypical antipsychotics versus conventional or typical antipsychotics provides } \\
\text { more benefits both through oral and parenteral administration }\end{array}$ & $92(56.8)$ & $55(34.0)$ & $9(5.6)$ & $4(2.5)$ & $2(1.2)$ \\
\hline $\begin{array}{l}\# 30 \text {. Use of haloperidol should be restricted to acute treatment of agitation or psychosis } \\
\text { with inability to use the oral route, need for intravenous route, or inability to administer } \\
\text { parenteral atypical antipsychotics }\end{array}$ & $74(45.7)$ & $71(43.8)$ & $6(3.7)$ & $9(5.6)$ & $2(1.2)$ \\
\hline \#36. Antipsychotics are useful in the treatment of anxiety in patients with dementia* & $17(11.0)$ & $111(71.6)$ & $11(7.1)$ & $12(7.7)$ & $4(2.6)$ \\
\hline \#37. Antipsychotics are useful in the treatment of euphoria in patients with dementia* & $37(23.9)$ & $96(61.9)$ & $15(9.7)$ & $6(3.9)$ & $1(0.6)$ \\
\hline \#41. In situations of euphoria with disinhibition, antipsychotics can be especially useful & $51(31.5)$ & $91(56.2)$ & $13(8.0)$ & $5(3.1)$ & $2(1.2)$ \\
\hline \#42. Antipsychotics are useful in the treatment of irritability & $37(22.8)$ & $89(54.9)$ & $19(11.7)$ & $16(9.9)$ & $1(0.6)$ \\
\hline $\begin{array}{l}\text { \#44. Atypical antipsychotics with a more sedative profile (quetiapine and olanzapine) are } \\
\text { useful for the treatment of insomnia in patients with dementia* }\end{array}$ & $67(41.4)$ & $81(50.0)$ & $5(3.1)$ & $7(4.3)$ & $2(1.2)$ \\
\hline $\begin{array}{l}\text { \#47. The use of long-acting atypical antipsychotics may be useful in some cases of dementia } \\
\text { with difficulties in adherence to treatment* }\end{array}$ & $37(23.9)$ & $92(59.4)$ & $7(4.5)$ & $14(9.0)$ & $5(3.2)$ \\
\hline
\end{tabular}

Numbers of the items are those of the study questionnaire (online suppl. material). Percentages in parenthesis. BPSD, behavioral and psychological symptoms of dementia. * Agreement/disagreement achieved on the second round.

with the assertion that 2 antipsychotics have a greater benefit than using high doses of any of them separately. No consensus was reached for the following 5 items: greater improvement of delusions with acetylcholinesterase inhibitors than with antipsychotics; atypical antipsychotics have clinical benefits on apathy; antipsychotics are generally the drugs of choice versus antidepressants or hormonal agents for the control of sexual disinhibition; atypical antipsychotics are not useful for the treatment of compulsive behavior; and aberrant motor behavior does not respond to treatment with antipsychotics.

\section{Safety and Tolerability of Antipsychotics}

Almost all participants (96.9\%) strongly or moderately agreed that atypical antipsychotics are safer and better tolerated than typical antipsychotics. No consensus was reached, neither in favor nor against, for haloperidol as the least safe antipsychotic in relation to the risk of mortality, or the fact that the risk of mortality is different for each atypical antipsychotic drug. There was consensus in favor of using quetiapine, aripiprazole, and clozapine in Lewy body dementia and dementias with parkinsonism because of a lower incidence of extrapyramidal side effects $(96.3 \%)$ and that poor tolerability and paradoxical effects of antipsychotics were more frequent in fragile and polymedicated patients (91.3\%). Most participants (89\%) disagreed with the statement that safety and tolerability of antipsychotics is similar in all types of dementia.

\section{Follow-Up and Control of Patients with BPSD}

In this section of the questionnaire (Table 3 ), consensus was reached in favor of performing laboratory tests and an electrocardiogram before prescribing antipsychotics, but there was disagreement on the requirement 
Table 3. Answers to the questionnaire items regarding follow-up and control of patients with BPSD

\begin{tabular}{|c|c|c|c|c|c|}
\hline Items of the questionnaire & \multicolumn{5}{|c|}{ 5-point Likert scale } \\
\hline $\begin{array}{l}\text { \#55. Before prescribing an antipsychotic to a patient with dementia, it is necessary to order } \\
\text { blood tests that include a hematology profile and blood biochemistry (hepatic, lipid, and } \\
\text { renal profile) }\end{array}$ & $64(39.8)$ & $60(37.3)$ & $19(11.8)$ & $17(10.6)$ & $1(0.6)$ \\
\hline $\begin{array}{l}\# 57 \text {. Before prescribing an antipsychotic to a patient with dementia, a neuroimaging study } \\
\text { is necessary as an aid to assess the cerebrovascular risk* }\end{array}$ & $4(2.6)$ & $24(15.5)$ & $22(14.2)$ & $83(53.5)$ & $22(14.2)$ \\
\hline $\begin{array}{l}\text { \#58. In patients with dementia on long-term treatment with an antipsychotic ( }>12 \text { weeks), } \\
\text { vital signs (weight, BMI, abdominal circumference, blood pressure, and heart rate) should } \\
\text { be controlled at least every } 3 \text { month }\end{array}$ & $61(38.1)$ & $74(46.3)$ & $17(10.6)$ & $8(5.0)$ & 0 \\
\hline $\begin{array}{l}\text { \#61. In patients with dementia on long-term treatment with an antipsychotic (>12 weeks), } \\
\text { it is necessary to monitor prolactin levels at least every 6-9 months* }\end{array}$ & $11(7.1)$ & $52(33.5)$ & $47(30.3)$ & $34(21.9)$ & $11(7.1)$ \\
\hline $\begin{array}{l}\text { \#62. In patients with dementia on long-term treatment with an antipsychotic ( }>12 \text { weeks), } \\
\text { the indication and doses of the drug should be revised at least every } 3 \text { months }\end{array}$ & $85(52.8)$ & $58(36.0)$ & $7(4.3)$ & $11(6.8)$ & 0 \\
\hline
\end{tabular}

Numbers of the items are those of the study questionnaire (online suppl. material). Percentages in parenthesis. BPSD, behavioral and psychological symptoms of dementia. * Agreement/disagreement achieved on the second round.

to conduct a neuroimaging study prior to prescribing antipsychotics as an aid to assess the cerebrovascular risk. Participants agreed that in patients on long-term treatment with antipsychotics ( $>12$ weeks), vital signs and the emergence of extrapyramidal effects should be monitored at least every 3 months. Moreover, there was consensus regarding the need to do blood tests with a hematology profile and blood biochemistry (hepatic, lipid, and renal profiles) at least every 9-12 months in these patients. Participants disagreed on the need of assessing plasma prolactin levels at least every 6-9 months. There was agreement on the importance to review the indication and dose of the antipsychotic drug at least every 3 months.

In relation to the recommendation for using individual antipsychotics for BPSD in different patient profiles based on their comorbidities, clozapine ( $88.4 \%)$, quetiapine $(87.6 \%)$, and aripiprazole $(76.8 \%)$ were considered as the preferred atypical antipsychotics of choice for patients with dementia and movement disorders. For patients with dementia and renal failure, quetiapine (90.9\%) and aripiprazole $(85.8 \%)$ were the drugs of choice, where- as for patients with concomitant liver dysfunction, there was agreement for the preferred use of aripiprazole (85.1\%). Finally, in patients with dementia and arrhythmia, consensus was reached for the use of aripiprazole $(86.5 \%)$ and quetiapine (76.8\%).

Barriers for the Correct Use of Atypical Antipsychotics Specific administrative barriers in Spain for the prescription of atypical antipsychotics were identified as a difficulty for the access of patients to these medications (83.2\% of respondents) and a factor that had led to the increased use of typical antipsychotics (77\%). Participants considered that the use of atypical antipsychotics in patients with BPSD should be protocolized (98.8\%). Also, $80.8 \%$ of participants agreed with the statement that although informed consent is required for the use of atypical antipsychotics, in many cases informed consent is not requested, a situation that generates a legal uncertainty. However, $49.2 \%$ of participants stated that medication was available through compassionate use in their regional hospital settings. 


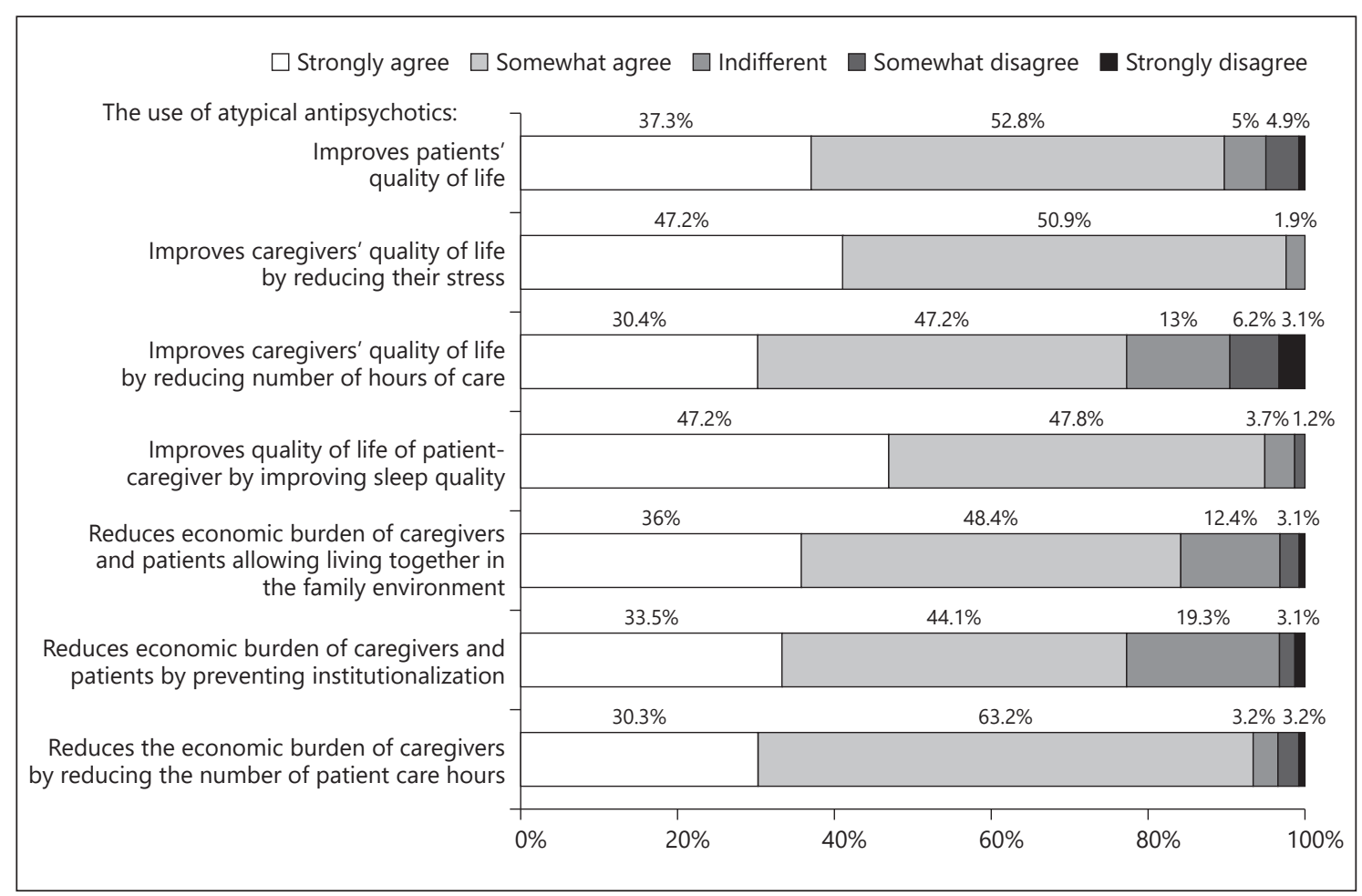

Fig. 1. Impact of atypical antipsychotics in the patients and caregivers quality of life.

\section{Quality of Life}

There was consistent high degree of agreement among participants on the beneficial impact of atypical antipsychotics for BPSD on all aspects of the quality of life of patients with dementia and their caregivers (Fig. 1).

\section{Discussion}

The present study aimed to achieve a consensus on the assessment and management of patients with BPSD. The questionnaire designed for the project covered 3 main aspects of BPSD, namely the detection of BPSD in patients with dementia, the follow-up and control of patients with BPSD, and more specifically, the indication of antipsychotics in different patient profiles with dementia. BPSD, an array of psychopathological features that commonly occur at the same time in a given patient, are associated with significant functional and clinical impairment and represent an important burden for both patients and their caregivers [1, 19-22]. In accordance with the literature [4, 19], all the participants (100\%) in the present study agreed on these statements and recognized the relevance of
BPSD and their negative impact on the quality of life for both patients and carers.

Participants agreed that in people aged 65 and over without a personal history of psychiatric disorders, the emergence of BPSD including hallucinations, delusional ideas, depression, apathy or indifference, irritability, emotional lability, or aberrant motor behavior is an indication to routinely screen for dementia. Panel members agreed with previous reports $[23,24]$ on the role of these symptoms in the prediction of cognitive decline. Screening identifies the existence and extent of cognitive impairment and provides a baseline to assess any decline or fluctuation in cognition that may be attributed to treatable causes. Participants considered that dementia with Lewy bodies was the most frequent type of dementia associated with visual hallucination. Similarly, in a systematic review and random-effects meta-analyses of studies reporting auditory and visual hallucinations associated with Parkinson's disease or dementia with Lewy bodies, the estimated pooled prevalence of auditory hallucinations was $8.9 \%$ in Parkinson's disease and $30.8 \%$ in dementia with Lewy bodies, while visual hallucinations were more common, with an estimated pooled preva- 
lence of $28.2 \%$ in Parkinson's disease and $61.8 \%$ in dementia with Lewy bodies [25].

In relation to results regarding treatment of BPSD, more than $90 \%$ of study participants agreed that prescribing anticholinesterase inhibitors/memantine before starting treatment with antipsychotics is a good clinical practice. However, a recent meta-analysis of the effects of these drugs on scores of the Mini-Mental State Examination (MMSE) as a common tool to monitor dementia in clinical practice showed only a modest effect [26]. An international Delphi consensus agreed on a clear preference for an escalating approach to the management of BPSD in $\mathrm{AD}$ commencing with the identification of underlying causes [27]. In addition, $85.8 \%$ of participants agreed regarding the statement that antipsychotic medications are only recommended in cases of severe and persistent or recurrent BPSD. For the remaining $14.2 \%$ of participants who neither agreed nor disagreed (4.5\%) or moderately disagreed (9.7\%), the questionnaire did not ask about the reasons for not recommending antipsychotics in such cases. Expert consensus suggesting use of antipsychotic drugs in individuals with dementia can be appropriate in cases with dangerous agitation or psychosis, and can be useful in minimizing the risk of violence, reducing patient distress, improving patient's quality of life, and reducing caregiver burden [28]. With respect to the benefits of atypical antipsychotics over conventional or typical ones, the participants expressed a high degree of agreement on the fact that atypical antipsychotics provide more benefits to patients, which agrees with data of a recent review of antipsychotic drugs for the treatment of BPSD in patients with dementia [29]. Indeed, atypical antipsychotics are generally preferred over conventional agents in treating BPSD because they have substantially lower risks of extrapyramidal neurological effects, such as parkinsonism or tardive dyskinesia [30]. However, a network metaanalysis found that no single atypical antipsychotic was consistently associated with better results than the others in the treatment of BPSD across all effectiveness and safety outcomes [16].

In patients with dementia with Lewy bodies and dementias with parkinsonism, panel participants recommended the atypical antipsychotics quetiapine, aripiprazole, and clozapine as the preferred options based on the lower rate of extrapyramidal side effects associated with these drugs. With regard to the selection of specific atypical antipsychotics for the management of different profiles of patients with BPSD, including movement disorders, renal failure, liver dysfunction, and cardiac arrhythmias, quetiapine was selected as the first option for treatment of patients with movement disorders or renal failure, in second place for cardiac arrhythmias. Aripiprazole was recommended in all these clinical scenarios, and clozapine in cases of movement disorders. However, comparative efficacy of atypical antipsychotics for BPSD in these subgroups of dementia patients is lacking. While antipsychotics are often used to treat BPSD, common use of these medications remains controversial due to relatively low effect sizes and the high risk of occurrence of adverse effects [31]. Specifically, the evidence on the benefits of particular antipsychotics in dementia with Lewy bodies or other dementias with parkinsonism is very limited; although due to its minor potential to induce extrapyramidal effects, quetiapine has been suggested to be appropriate for the treatment of BPSD in these types of dementia [32]. "Real world" consensus like the present study is pleaded for a rationale use of these drugs.

In the current context of the Spanish public health care system, participants almost unanimously recognized that administrative barriers to the prescription of atypical antipsychotics increase the use of first-generation antipsychotics, with a less favorable profile of motor side effects and no advantages at cerebrovascular level, and this may also be the case in other countries. However, the importance of specific administrative barriers for prescription of atypical antipsychotics cannot be generalized to other health care systems with characteristics and organizations different from the framework of the present study. Therefore, the external validity of this finding is limited. In accordance with previous reports [26, 33], there was also consensus in our study regarding the need to have protocols for the use of atypical antipsychotics for BPSD in order to help physicians in clinical practice and in benefit of patients and their families, a finding that could indicate an insufficient knowledge or application of guidelines in practice [34-36].

The present findings should be interpreted taking into account some limitations particularly that the survey reflects opinions not facts, and that information regarding specialists who did not participate was not recorded. Also, although it would have been interesting to discuss the use of antipsychotics for the management of the different symptoms which are under the umbrella of BPSD, detailed information of antipsychotic agents by symptom is beyond the scope of the present discussion.

In summary, the present study reports useful information provided by specialists on various relevant aspects related to the management of patients with BPSD in Spain. The study highlights the importance the specialist 
participants in the study give to early identification of the spectrum of symptoms of BPSD in individuals with dementia, considering the significance that they have on the quality of life of patients and caregivers. Consequently, in an elderly patient who develops BPSD without a history of psychiatric problems, screening for dementia becomes mandatory. Participants considered that use of antipsychotics for managing BPSD is associated with important benefits in the overall quality of life of patients and the carers.

\section{Acknowledgements}

The authors thank Grupo Saned, S.L., for logistic support and Marta Pulido, $\mathrm{MD}, \mathrm{PhD}$, for editing the manuscript and editorial assistance.

\section{Statement of Ethics}

According to regulations of the Spanish Agency of Medicines and Medical Devices (AEMPS), procedures described in the order SAS/3470/2009 of December and in the royal decree 1090/2015 of December 4 regarding postauthorization studies and clinical trials with drugs, respectively, are not applicable. The study is therefore exempt from requiring approval by a Clinical Research Ethics Committee (CEIC) and by the AEMPS.

\section{Conflict of Interest Statement}

The authors have no conflicts of interest to declare.

\section{Funding Sources}

The study was supported by an unrestricted educational grant from NEURAXPHARM SPAIN, S.L., Sant Joan Despí, Barcelona, Spain. The funder had no role in the study design, data collection and analysis, decision to publish, or writing of the manuscript.

\section{Author Contributions}

S. Manzano-Palomo, L.F. Agüera-Ortiz, A. García-Caballero, J. Martínez-Raga, T. Ojea-Ortega, R. Sánchez-Valle, M. AntónJiménez, J.A. Monge-Argilés, and I. Ramos-García formed the scientific committee of the study, designed the questionnaire, supervised the recruitment of participants, analyzed data, revised the manuscript for intellectual content, and approved the final draft.

\section{References}

1 Anand A, Khurana P, Chawla J, Sharma N, Khurana N. Emerging treatments for the behavioral and psychological symptoms of dementia. CNS Spectr. 2018;23(6):361-9.

2 Finkel SI, Costa e Silva J, Cohen G, Miller S, Sartorius N. Behavioral and psychological signs and symptoms of dementia: a consensus statement on current knowledge and implications for research and treatment. Int Psychogeriatr. 1996;8(Suppl 3):497-500.

3 Ford AH. Neuropsychiatric aspects of dementia. Maturitas. 2014;79(2):209-15.

4 Zhao Q-F, Tan L, Wang H-F, Jiang T, Tan $M-S$, Tan L, et al. The prevalence of neuropsychiatric symptoms in Alzheimer's disease: systematic review and meta-analysis. J Affect Disord. 2016;190:264-71.

5 Cerejeira J, Lagarto L, Mukaetova-Ladinska EB. Behavioral and psychological symptoms of dementia. Front Neurol. 2012;3:73.

6 Kales HC, Gitlin LN, Lyketsos CG. Detroit expert panel on assessment and management of neuropsychiatric symptoms of dementia. Management of neuropsychiatric symptoms of dementia in clinical settings: recommendations from a multidisciplinary expert panel. J Am Geriatr Soc. 2014;62(4):762-9.

7 Shinosaki K, Nishikawa T, Takeda M. Neurobiological basis of behavioral and psychological symptoms in dementia of the Alzheimer type. Psychiatry Clin Neurosci. 2000;54(6):611-20.
8 Kar N. Behavioral and psychological symptoms of dementia and their management. Indian J Psychiatry. 2009;51(Suppl 1):S77-86.

9 Pérez-Romero A, González Garrido S. The importance of behavioural and pyschological symptoms in Alzheimer disease. Neurologia. 2018;33(6):378-84.

10 Tible OP, Riese F, Savaskan E, von Gunten A. Best practice in the management of behavioural and psychological symptoms of dementia. Ther Adv Neurol Disord. 2017;10(8): 297-309.

11 Davies SJ, Burhan AM, Kim D, Gerretsen P, Graff-Guerrero A, Woo VL, et al. Sequential drug treatment algorithm for agitation and aggression in Alzheimer's and mixed dementia. J Psychopharmacol. 2018;32(5): 509-23.

12 Forester BP, Vahia I. Behavioral and psychological symptoms: an emerging crisis of the Alzheimer dementia epidemic. JAMA Netw Open. 2019;2(3):e190790.

13 Fernández-Domínguez MJ, Hernández Gómez MA, Garrido Barral A, González Moneo MJ. Making balances between the risks and benefits of pharmacological treatment in dementia, chronic pain and anticoagulation in elderly persons. Aten Prim. 2018;50(Suppl 2): 39-45.

14 Schneider LS, Dagerman KS, Insel P. Risk of death with atypical antipsychotic drug treat- ment for dementia: meta-analysis of randomized placebo-controlled trials. JAMA. 2005; 294(15):1934-43.

15 Kales HC, Kim HM, Zivin K, Valenstein M, Seyfried LS, Chiang C, et al. Risk of mortality among individual antipsychotics in patients with dementia. Am J Psychiatry. 2012;169(1): 71-9.

16 Yunusa I, Alsumali A, Garba AE, Regestein QR, Eguale T. Assessment of reported comparative effectiveness and safety of atypical antipsychotics in the treatment of behavioral and psychological symptoms of dementia: a network meta-analysis. JAMA Netw Open. 2019;2(3):e190828.

17 Graham B, Regehr G, Wright JG. Delphi as a method to establish consensus for diagnostic criteria. J Clin Epidemiol. 2003;56(12):11506.

18 Diamond IR, Grant RC, Feldman BM, Pencharz PB, Ling SC, Moore AM, et al. Defining consensus: a systematic review recommends methodologic criteria for reporting of Delphi studies. J Clin Epidemiol. 2014;67(4): 401-9.

19 Matsumoto N, Ikeda M, Fukuhara R, Shinagawa S, Ishikawa T, Mori T, et al. Caregiver burden associated with behavioral and psychological symptoms of dementia in elderly people in the local community. Dement Geriatr Cogn Disord. 2007;23(4):219-24.
Antipsychotics for Behavioral and

Psychological Symptoms of Dementia 
20 Huang SS, Lee MC, Liao YC, Wang WF, Lai TJ. Caregiver burden associated with behavioral and psychological symptoms of dementia (BPSD) in Taiwanese elderly. Arch Gerontol Geriatr. 2012;55(1):55-9.

21 Taemeeyapradit U, Udomittipong D, Tepparak N. Characteristics of behavioral and psychological symptoms of dementia, severity and levels of distress on caregivers. J Med Assoc Thai. 2014;97(4):423-30.

22 Hurt C, Bhattacharyya S, Burns A, Camus V, Liperoti R, Marriott A, et al. Patient and caregiver perspectives of quality of life in dementia. An investigation of the relationship to behavioural and psychological symptoms in dementia. Dement Geriatr Cogn Disord. 2008; 26(2):138-46.

23 Creese B, Brooker H, Ismail Z, Wesnes KA, Hampshire A, Khan Z, et al. Mild behavioral impairment as a marker of cognitive decline in cognitively normal older adults. Am J Geriatr Psychiatry. 2019;27(8):823-34.

24 Beaudreau SA, Kaci Fairchild J, Spira AP, Lazzeroni LC, O'Hara R. Neuropsychiatric symptoms, apolipoprotein E gene, and risk of progression to cognitive impairment, no dementia and dementia: the aging, demographics, and memory study (ADAMS). Int J Geriatr Psychiatry. 2013;28(7):672-80.
25 Eversfield CL, Orton LD. Auditory and visual hallucination prevalence in Parkinson's disease and dementia with Lewy bodies: a systematic review and meta-analysis. Psychol Med. 2019 Oct;49(14):2342-53.

26 Knight R, Khondoker M, Magill N, Stewart R, Landau S. A systematic review and meta-analysis of the effectiveness of acetylcholinesterase inhibitors and memantine in treating the cognitive symptoms of dementia. Dement Geriatr Cogn Disord. 2018;45(3-4):131-51.

27 Kales HC, Lyketsos CG, Miller EM, Ballard C. Management of behavioral and psychological symptoms in people with Alzheimer's disease: an international Delphi consensus. Int Psychogeriatr. 2019;31(1):83-90.

28 Reus VI, Fochtmann LJ, Eyler AE, Hilty DM, Horvitz-Lennon M, Jibson MD, et al. The American psychiatric association practice guideline on the use of antipsychotics to treat agitation or psychosis in patients with dementia. Am J Psychiatry. 2016;173(5):543-6.

29 Ohno Y, Kunisawa N, Shimizu S. Antipsychotic treatment of behavioral and psychological symptoms of dementia (BPSD): management of extrapyramidal side effects. Front Pharmacol. 2019;10:1045.

30 Gurevich A, Guller V, Berner YN, Tal S. Are atypical antipsychotics safer than typical antipsychotics for treating behavioral and psychological symptoms of dementia? J Nutr Health Aging. 2012;16(6):557-61.
31 Masopust J, Protopopová D, Vališ M, Pavelek Z, Klímová B. Treatment of behavioral and psychological symptoms of dementias with psychopharmaceuticals: a review. Neuropsychiatr Dis Treat. 2018;14:1211-20.

32 Armstrong MJ, Weintraub D. The case for antipsychotics in dementia with Lewy bodies. Mov Disord Clin Pract. 2016;4(1):32-5.

33 Ambrogio F, Martella LA, Odetti P, Monacelli F. Behavioral disturbances in dementia and beyond: time for a new conceptual frame? Int J Mol Sci. 2019;20(15):E3647.

34 Sadowsky CH, Galvin JE. Guidelines for the management of cognitive and behavioral problems in dementia. J Am Board Fam Med. 2012;25(3):350-66

35 Sorbi S, Hort J, Erkinjuntti T, Fladby T, Gainotti G, Gurvit H, et al. EFNS-ENS Guidelines on the diagnosis and management of disorders associated with dementia. Eur J Neurol. 2012;19(9): 1159.

36 Tratamiento farmacológico de los síntomas psicológicos y conductuales de la demencia (Pharmacological treatment of psychological and behavioural symptoms of dementia) (last revision February 3, 2016). Available from: https: //www.fisterra.com/guias-clinicas/tratamiento-farmacologico-sintomas-psicologicos-conductuales-demencia/ Accessed 2020 May 8. 